Article

\title{
Optimizing Photoperiod, Exposure Time, and Host-to-Parasitoid Ratio for Mass-Rearing of Telenomus remus, an Egg Parasitoid of Spodoptera frugiperda, on Spodoptera litura Eggs
}

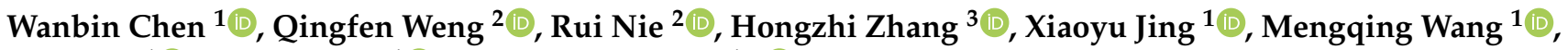 \\ Yuyan Li ${ }^{1} \mathbb{D}$, Jianjun Mao ${ }^{1} \mathbb{D}$ and Lisheng Zhang ${ }^{1, *} \mathbb{D}$ \\ 1 State Key Laboratory for Biology of Plant Diseases and Insect Pests, Institute of Plant Protection, \\ Chinese Academy of Agricultural Sciences, Beijing 100193, China; chenwb24@126.com (W.C.); \\ jingxiaoyu1996@163.com (X.J.); wangmengqing@caas.cn (M.W.); liyuyan@caas.cn (Y.L.); \\ jianjunmao@ippcaas.cn (J.M.) \\ 2 College of Plant Protection, Henan Agricultural University, Zhengzhou 450002, China; \\ 17337619318@163.com (Q.W.); nierui0721@163.com (R.N.) \\ 3 Department of Entomology and BIO5 Institute, University of Arizona, Tucson, AZ 85721, USA; \\ zhanghz@email.arizona.edu \\ * Correspondence: zhanglisheng@caas.cn; Tel.: +86-10-6281-5909
}

\section{check for} updates

Citation: Chen, W.; Weng, Q.; Nie, R.; Zhang, H.; Jing, X.; Wang, M.; Li, Y.; Mao, J.; Zhang, L. Optimizing Photoperiod, Exposure Time, and Host-to-Parasitoid Ratio for Mass-Rearing of Telenomus remus, an Egg Parasitoid of Spodoptera frugiperda, on Spodoptera litura Eggs. Insects 2021, 12, 1050. https:// doi.org/10.3390/insects12121050

Academic Editor: Sergey Ya Reznik

Received: 25 October 2021

Accepted: 22 November 2021

Published: 24 November 2021

Publisher's Note: MDPI stays neutral with regard to jurisdictional claims in published maps and institutional affiliations.

Copyright: (c) 2021 by the authors. Licensee MDPI, Basel, Switzerland. This article is an open access article distributed under the terms and conditions of the Creative Commons Attribution (CC BY) license (https:/ / creativecommons.org/licenses/by/ $4.0 /)$.
Simple Summary: Telenomus remus (Nixon) is a promising natural enemy of Spodoptera frugiperda (J. E. Smith). Successful implementation of a biocontrol program requires a mature rearing system to produce millions of beneficial insect products at lower costs. This parasitoid is successfully reared on Corcyra cephalonica (Stainton) eggs in several countries, however that host species is unsuitable for Chinese strains of T. remus. Fewer studies have been done using Spodoptera litura (Fabricius) eggs, but it is increasingly seen as the promising alternative host in China. In order to identify optimal mass-rearing conditions when using $S$. litura eggs as an alternative host, this novel study thus sought to comprehensively evaluate the effects of photoperiod, exposure time, and host egg:parasitoid ratio on the reproductive potential and mass-rearing efficiency of T. remus on S. litura eggs. Our results suggest using more than $12 \mathrm{~h}$ of light, $24 \mathrm{~h}$ exposure time, and 14-20:1 host egg:parasitoid ratio for rearing T. remus on S. litura eggs. These findings will help promote successful, large-scale rearing of T. remus for use against $S$. frugiperda in China.

Abstract: Telenomus remus (Nixon) is a dominant egg parasitoid of the destructive agricultural pest Spodoptera frugiperda (J. E. Smith), and so is used in augmentative biocontrol programs in several countries. An optimized mass-rearing system is essential to produce biological control products in a timely and cost-effective manner. In this study, the photoperiod, host egg:parasitoid ratio, and exposure time were evaluated to identify the optimal rearing conditions for T. remus on the alternative host Spodoptera litura (Fabricius) eggs. Results showed that increasing photoperiod above 12L:12D remarkably improved parasitoid progeny yield and life table parameters. Overlong photoperiods shortened female longevity, but within acceptable limits. There was a significant negative correlation between parasitism rate and host egg:parasitoid ratio under exposure times of 12 and $36 \mathrm{~h}$, but not $24 \mathrm{~h}$. Percentage of female progeny increased significantly along with increasing the host egg:parasitoid ratio. A significant negative relationship between the number of emerged adults per egg and the host egg:parasitoid ratio was observed at an exposure time of $36 \mathrm{~h}$. It was concluded that $T$. remus may be mass-reared most efficiently on S. litura eggs using a photoperiod of more than 12L:12D, a 14-20:1 host egg:parasitoid ratio, and an exposure time of $24 \mathrm{~h}$. These findings can be used to produce $T$. remus more efficiently and at lower costs.

Keywords: mass-rearing efficiency; biological control; host egg-to-parasitoid ratio; photoperiod; exposure time; production costs 


\section{Introduction}

Spodoptera frugiperda (J. E. Smith) is an indigenous species in America [1], but has spread to 44 African countries [2] and several Asian countries [3] in less than three years since it first invaded Africa in 2016 [4]. Field investigations first detected it in China in January 2019 [5]. By September 2020, it had spread to 27 provinces (autonomous regions and municipalities) across the country [6]. Such invasive insects have considerable negative influences on their new environments, damaging indigenous plant species and becoming major agricultural pests [7]. The economic losses caused by invasive insects, in general, are estimated to be about US\$1.3 trillion per year worldwide [8], and S. frugiperda is widely agreed to be one of the major devastating invasive pests $[3,9,10]$. Its larvae are highly polyphagous with over 353 recorded host plants, such as corn, wheat, rice, cotton, potato, onion, and sorghum [11]. It poses a particular threat to corn production in many countries, which is the third most cultivated grain in the world $[12,13]$. In Africa, this pest has been calculated to cause annual yield losses in corn of $21-53 \%$, with the financial losses estimated at approximately US\$2.48-6.19 billion [9].

At present, synthetic chemical pesticides are still the most common and effective emergency method for S. frugiperda control [14]. Predictably, long-term pesticide application comes with insecticide resistance, secondary pest outbreaks, elimination of natural enemies, and potential environmental and human health challenges $[15,16]$. With the realization of adverse effects associated with the application of chemical pesticides, agriculture is gradually transforming to more eco-friendly and sustainable pest control techniques [17]. The biological control of insect pests is a vital component of integrated pest management, and provides a self-sustaining strategy for the management of alien invasive pests [7] Correspondingly, the Chinese government has launched a series of research programs to advocate the reduced application of conventional pesticides and support the development of sustainable agriculture [15]. Therefore, it is necessary to develop an ecologically safe and sustainable strategy for the control of S. frugiperda.

Telenomus remus (Nixon) is a promising egg parasitoid widely applied in the Americas to control S. frugiperda [18-20]. In Honduras, releasing 35,000-105,000 T. remus wasps/ha/week resulted in $20 \%$ to $92 \%$ of eggs in maize and sorghum being parasitized [19]. In Brazil, the maximal parasitism rate after T. remus release at phenological stages $\mathrm{V}_{4}$ and $\mathrm{V}_{10}$ in corn, vegetative, and reproductive stages in cotton, and vegetative and reproductive stages in soybean fields respectively reached $99.8 \%$ and $96.8 \%, 77.8 \%$ and $73.1 \%$, and $77.3 \%$ and $54.4 \%$ [21]. Such success is due in large part to its excellent ability to overcome the scales covering $S$. frugiperda egg masses and parasitize the eggs arranged in the inner layer $[19,22]$.

Successful implementation of a biological control program requires a well-developed rearing system that can mass-produce millions of beneficial insect products while efficiently using resources, space, and time $[15,23]$. Production efficiency and cost are thus key issues affecting the development of the biological control industry [24].

The identification of a suitable host is necessary to develop a parasitoid mass-rearing system, which will be optimized specifically for that parasitoid-host interaction. Several reports have studied the ideal rearing methods and conditions for T. remus on Corcyra cephalonica (Stainton) eggs [25-28], a feasible host in certain parts of the world. In addition, eggs of Agrotis biconica (Kollar), A. ipsilon (Hufnagel), S. exigua (Hübner), S. littoralis (Boisduval), and other Lepidoptera species have also been served as hosts [19]. However, Chinese studies found that the indigenous population of $T$. remus cannot parasitize $C$. cephalonica eggs, making this host unsuitable in China [29,30]. The authors speculated that this may be because wild-caught $T$. remus bred on the natural hosts cannot recognize and parasitize the C. cephalonica eggs after being taken into a laboratory [30]. Chinese reports have suggested Spodoptera litura (Fabricius) eggs as a candidate host. Our prior study evaluated the biological parameters of T. remus reared on S. litura eggs, such as development, thermal requirement, parasitism, and offspring fitness, and the results verified the feasibility of this alternative host [31]. The next step, in order to reduce production 
costs, is to do a series of tests to carefully assess the effects of different factors on mass production efficiency in the environment of a laboratory [32] and eventually identify the optimal mass-rearing conditions.

Among several such factors, exposure time and the host egg:parasitoid ratio impact the reproductive efficiency of parasitoids in mass production systems [32-34]. Several studies focused on the effects of these two factors on other parasitoids, including Sclerodermus pupariae (Yang \& Yao) [34], Ontsira mellipes (Ashmead) [33], and Trichogramma [24], and found that unsuitable times and ratios can reduce rearing efficiency to different degrees. For example, although approximately 50-260 Trichogramma dendrolimi (Matsumura) can emerge from one Antheraea pernyi (Guérin-Mèneville) egg, the offspring body size, female ratio, longevity, and reproductive capacity will decrease if too many adults emerge from each egg [35]. To avoid degeneration and superparasitism, it is essential to identify a suitable exposure time and host egg:parasitoid ratio during mass production; in the above system, the optimal host egg:parasitoid ratio is 1:2, and the optimal exposure time is less than $24 \mathrm{~h}$ [35]. In addition, it is necessary to study the impact of abiotic factors on the biological characteristics of parasitoids to maximize mass production efficiency [36]. Although the role of temperature $[31,37]$ and relative humidity $[28,38]$ on parasitism and development are known, there is a gap in knowledge about the effect of photoperiod on the biology of T. remus on S. litura eggs.

Therefore, in order to achieve the best production levels that satisfy the needs from the field at lower costs, this study aimed to measure the effect of photoperiod, exposure time, and the host egg:parasitoid ratio on the parasitism rate, emergence rate, percentage of female progeny, and other biological parameters of T. remus reared on S. litura eggs.

\section{Materials and Methods}

\subsection{Insects}

The larvae of S. frugiperda were collected in 2019 from Kunming, Yunnan Province, China. The first to third instar young larvae were reared together in rectangular containers ( $34 \mathrm{~cm}$ length $\times 22 \mathrm{~cm}$ width $\times 4 \mathrm{~cm}$ height) and provided with fresh corn leaves. While fourth to sixth instar old larvae were reared individually by an artificial diet [39] in cylindrical boxes ( $3 \mathrm{~cm}$ height $\times 5 \mathrm{~cm}$ diameter). The component and preparation of the artificial diet were referred to those described by Greene et al. [39] with a slight modification; the pinto beans were replaced with soybean powder. Once adults emerged, they were placed in cylindrical wire-mesh cages $(24 \mathrm{~cm}$ diameter $\times 28 \mathrm{~cm}$ height) with wet gauze and wax paper as oviposition substrates and $20 \%$ honey solution provided as food. The substrates with egg masses were collected daily for subsequent experimentation. The population was maintained in a climatic incubator at $28 \pm 1{ }^{\circ} \mathrm{C}, 60 \pm 5 \%$ relative humidity $(\mathrm{RH})$, and 16:8 Light (L):Dark (D). All the climatic incubators (RXZ-500) used in this study were manufactured by the Ningbo Jiangnan Instrument Factory, Zhejiang Province, China.

Eggs of S. litura were originally purchased from the Jilin Academy of Agricultural Sciences, Jilin Province, China. The artificial diet for raising S. litura was prepared according to the formula reported by Chen et al. [40]. The feeding technology and conditions were the same as those of $S$. frugiperda as mentioned above. In order to ensure the availability of experimental materials, we continuously and large-scale raised the population.

T. remus were obtained from a colony maintained in the corn pest laboratory at the Institute of Plant Protection, Chinese Academy of Agricultural Sciences, in Beijing. The founder specimens were originally collected in 2019 from Jinhua, Zhejiang Province, China. Adult parasitoids were released in plastic tubes $(10 \mathrm{~cm}$ height $\times 2.5 \mathrm{~cm}$ diameter $)$ containing egg masses of the host $S$. frugiperda and fed with $20 \%$ honey solution under $26 \pm 1{ }^{\circ} \mathrm{C}$, $70 \pm 5 \% \mathrm{RH}$, and 14L: 10D.

\subsection{Parasitism and Fitness of T. remus under Different Photoperiods}

The following seven photoperiods (L:D) were tested: 0:24, 4:20, 8:16, 12:12, 16:8, 20:4, and 24:0. A single mated female parasitoid emerged within $24 \mathrm{~h}$ and was introduced into a 
plastic tube $(10 \mathrm{~cm}$ height $\times 2.5 \mathrm{~cm}$ diameter $)$ containing a drop of $20 \%$ honey solution in the inner surface, and then one paper card with approximately $160 \mathrm{~S}$. litura eggs (based on the known daily parasitism rate of T. remus on S. litura eggs [31]) was placed into the tube. All trials were conducted in the same temperature and relative humidity as mentioned above for T. remus rearing, differing only in the photoperiod. The female parasitoid was checked daily to measure her longevity, and the egg card was refreshed daily until her death. The parasitized eggs were moved into a new tube and maintained at the same conditions until emergence. Any S. litura larvae hatched from unparasitized eggs were removed in a timely manner to keep them from eating other eggs. The observation of parasitism and fitness was repeated five times, with each five wasps as a replicate. The total number of parasitized eggs/female and the emergence rate and percentage of female progeny were recorded.

\subsection{Effects of Exposure Time and Host Density}

To identify the optimal host egg:parasitoid ratio, and optimal duration of exposure to parasitoids, the completely randomized design had two factors: Exposure time with three levels (12, 24, and $36 \mathrm{~h})$ and host egg:parasitoid ratio with 11 levels (1:1, 2:1, 4:1, 6:1, 8:1, 10:1, $12: 1,14: 1,16: 1,18: 1$, and 20:1), for a total of 33 treatments. Approximately 80 mated female parasitoids within $24 \mathrm{~h}$ since emergence were released in tubes containing $S$. litura eggs (less than $24 \mathrm{~h}$ of age) based on the ratio described above. Therefore, the corresponding host densities were 80, 160, 320, 480, 640, 800, 960, 1120, 1280, 1440, and 1600 eggs. The parasitism conditions were maintained in $26 \pm 1^{\circ} \mathrm{C}$ and $70 \pm 5 \% \mathrm{RH}$, which are the optimal conditions as identified in our previous study [31]. However, the photoperiod was set as $24 \mathrm{~h}$ light, as T. remus is mostly inactive in the dark based on above photoperiod trials, and the phenomenon was also observed while maintaining the population. After the set exposure time, the parasitized eggs were removed into a new tube for development. Once offspring emerged, the number of female and male parasitoids and number of parasitized eggs were recorded. All treatments were replicated five times.

\subsection{Statistical Analysis}

One-way Analysis of Variance (ANOVA) was employed to determine the effects of photoperiod on the total number of parasitized eggs, longevity, emergence rate, and percentage of female progeny, and the means were compared using Tukey's honest significant difference (HSD) test at a 0.05 significance level. Life table parameters of the intrinsic rate of increase $\left(r_{m}\right)$, finite rate of increase $(\lambda)$, net reproductive rate $\left(R_{0}\right)$, and the mean generation time $(T)$ for each photoperiod were estimated using the methods mentioned by Huang et al. [41].

The interactive effects between exposure time and host egg:parasitoid ratio on parasitism rate, emergence rate, percentage of female progeny, and the number of emerged adults per egg were analyzed by two-way ANOVA. The relationship between the biological parameters mentioned above and host egg:parasitoid ratio was fitted by linear regression. All percentages were arcsine square-root-transformed to homogenize the variances before analysis, while the data for the number of parasitized eggs, longevity, and number of emerged adults per egg were log 10-transformed. All analyses were carried out in SPSS version 19.0 (IBM Corp., Chicago, IL, USA), and the figures were drawn in GraphPad Prism version 8.0 (GraphPad Software, Inc., San Diego, CA, USA).

\section{Results}

\subsection{Effect of Photoperiod on Parasitoid Performance}

The total number of parasitized eggs differed significantly among different photoperiods $(\mathrm{F}=36.315 ; \mathrm{df}=6,28 ; p<0.0001)$. Mean fecundity of $T$. remus under constant dark conditions (0L:24D) was lowest, which was significantly lower than all photoperiods tested in this study. Overall, the total number of parasitized eggs increased with longer photoperiods (Figure 1A). The photoperiod also had significant impacts on female longevity 
$(\mathrm{F}=5.960 ; \mathrm{df}=6,28 ; p<0.0001)$. The longevity ranged from 9.0 to 13.4 days. The longevity of females reared under constant illumination (24L:0D) was significantly shorter than under photoperiods of 0:24, 8:16, or 16:8 L:D (Figure 1B).
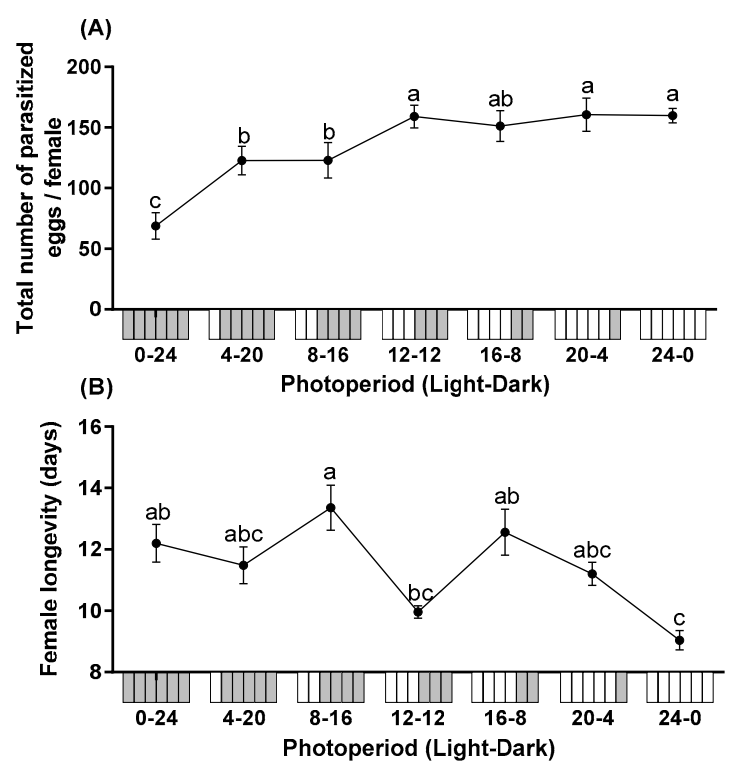

Figure 1. The total number of parasitized eggs per female (A) and longevity (B) of T. remus using S. litura eggs as alternative host under the different photoperiods. Data are represented as mean \pm SE. Different lowercase letters indicate significant differences among several photoperiods at $\alpha=0.05$ (Tukey test).

Photoperiod did not significantly affect the emergence rate $(\mathrm{F}=1.908 ; \mathrm{df}=6,28$; $p=0.115)$ or percentage of female progeny $(\mathrm{F}=1.572 ; \mathrm{df}=6,28 ; p=0.192)$. The emergence rate across all treatments ranged from $97.57 \%$ to $98.90 \%$ (Figure $2 \mathrm{~A}$ ). The progeny of T. remus was female-biased in all photoperiods with $>68.50 \%$ of progeny being female (Figure $2 \mathrm{~B}$ ).

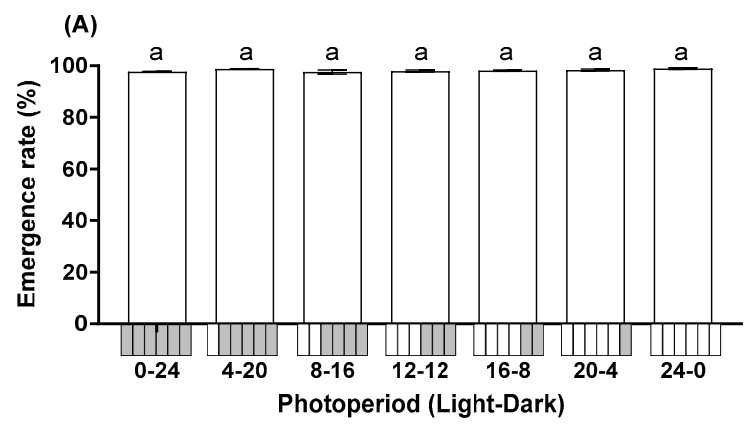

(B)

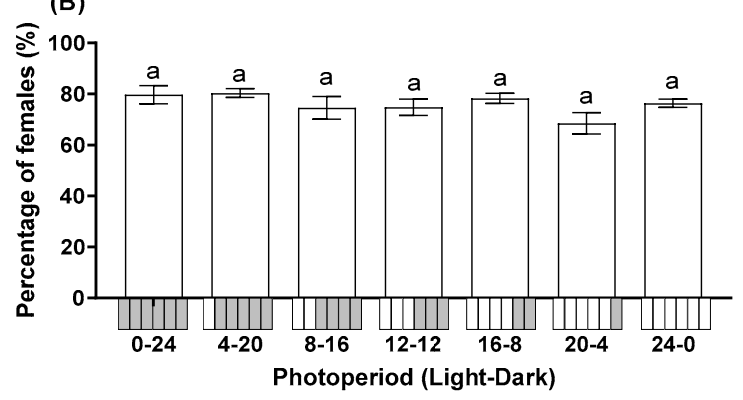

Figure 2. Influence of photoperiod on the emergence rate (A) and percentage of female progeny (B) of T. remus using $S$. litura eggs as the alternative host. Data are represented as mean \pm SE. Different lowercase letters indicate significant differences among several photoperiods at $\alpha=0.05$ (Tukey test). 


\subsection{Life table of T. remus under Different Photoperiods}

Life table parameter statistics found that the photoperiod of 24L:0D was preferable compared with other photoperiods tested. As a result of shortened mean generation time and higher parasitism potential, T. remus reared with constant light had the highest net reproductive rate, intrinsic rate of increase, and finite rate of increase. The worst performance of T. remus was observed in the photoperiod of 0L:24D (Table 1). Age-specific survival rate and the number of daughters generated per female of T. remus under different tested photoperiods are illustrated in Figure 3. The number of daughter/female/day was highest on the first day under all of the tested photoperiods. The survival rate of females began to decrease strongly, approximately eight days post-emergence.

Table 1. Life table parameters of T. remus on S. litura eggs under different photoperiods $(n=5)$.

\begin{tabular}{ccccc}
\hline \multirow{2}{*}{$\begin{array}{c}\text { Photoperiod } \\
\text { (Light-Dark) }\end{array}$} & $\begin{array}{c}\text { Net Reproductive Rate } \\
\left(\boldsymbol{R}_{\mathbf{0}}\right)\end{array}$ & $\begin{array}{c}\text { Intrinsic Rate of Increase } \\
\left(\boldsymbol{r}_{\boldsymbol{m}}\right)\end{array}$ & $\begin{array}{c}\text { Finite Rate of Increase } \\
(\boldsymbol{\lambda})\end{array}$ & $\begin{array}{c}\text { Mean Generation } \\
\text { Time }(\boldsymbol{T})\end{array}$ \\
\hline $0-24$ & $55.16 \pm 2.93 \mathrm{~d}$ & $0.354 \pm 0.021 \mathrm{~b}$ & $1.424 \pm 0.029 \mathrm{~b}$ & $11.5 \pm 0.7 \mathrm{ab}$ \\
$4-20$ & $97.81 \pm 3.26 \mathrm{bc}$ & $0.383 \pm 0.016 \mathrm{~b}$ & $1.470 \pm 0.023 \mathrm{~b}$ & $12.0 \pm 0.5 \mathrm{ab}$ \\
$8-16$ & $88.40 \pm 3.86 \mathrm{c}$ & $0.359 \pm 0.020 \mathrm{~b}$ & $1.432 \pm 0.029 \mathrm{~b}$ & $12.6 \pm 0.6 \mathrm{a}$ \\
$12-12$ & $117.96 \pm 6.75 \mathrm{a}$ & $0.414 \pm 0.013 \mathrm{ab}$ & $1.514 \pm 0.019 \mathrm{ab}$ & $11.5 \pm 0.3 \mathrm{ab}$ \\
$16-8$ & $116.08 \pm 3.82 \mathrm{a}$ & $0.395 \pm 0.013 \mathrm{ab}$ & $1.484 \pm 0.019 \mathrm{ab}$ & $12.1 \pm 0.3 \mathrm{ab}$ \\
$20-4$ & $107.96 \pm 3.33 \mathrm{ab}$ & $0.423 \pm 0.019 \mathrm{ab}$ & $1.526 \pm 0.029 \mathrm{ab}$ & $11.1 \pm 0.5 \mathrm{ab}$ \\
$24-0$ & $125.20 \pm 1.89 \mathrm{a}$ & $0.463 \pm 0.007 \mathrm{a}$ & $1.590 \pm 0.010 \mathrm{a}$ & $10.4 \pm 0.1 \mathrm{~b}$ \\
F & 36.631 & 5.524 & 5.944 & 2.167 \\
$\mathrm{df}$ & 6,28 & 6,28 & 6,28 & 6,28 \\
$p$ & $<0.0001$ & 0.001 & $<0.0001$ & 0.077 \\
\hline
\end{tabular}

Data are expressed as mean \pm SE. Data in a column followed by different letters are significantly different at $\alpha=0.05$ (Tukey test).
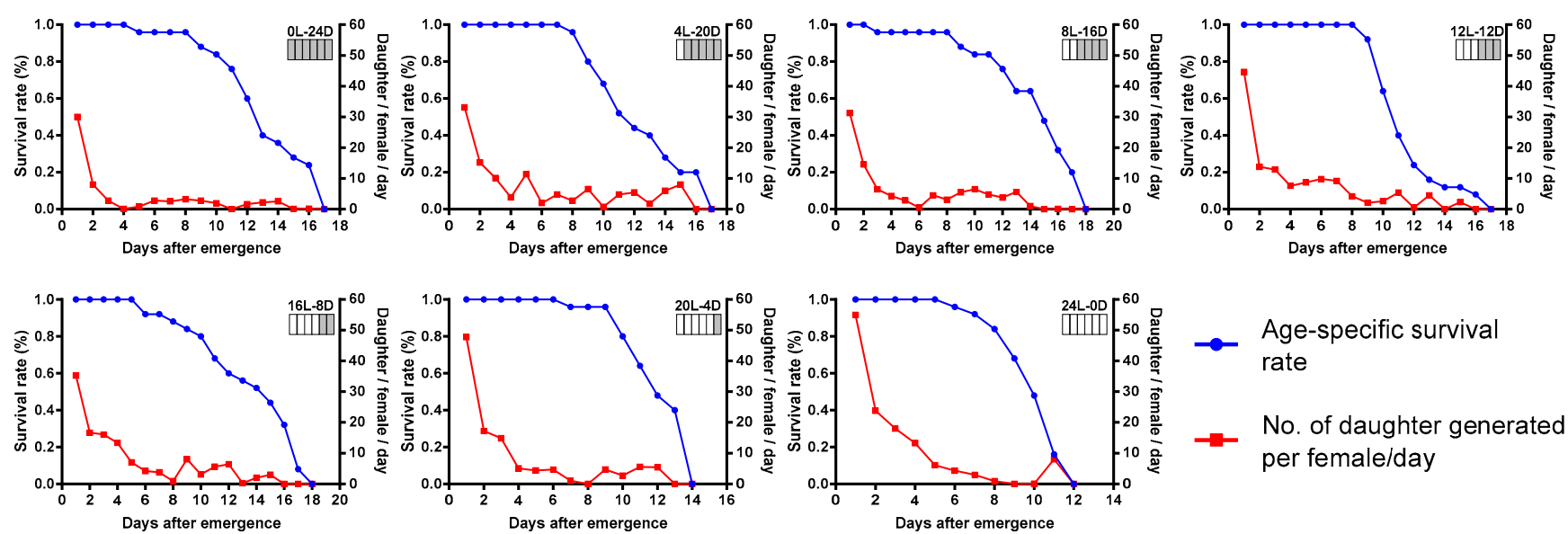

Figure 3. Age-specific survival rate of T. remus and number of daughters generated per female per day under different photoperiods.

\subsection{Parasitism Rate of T. remus under Different Combinations of Exposure Time and Host Egg:Parasitoid Ratio}

Telenomus remus parasitism on S. litura eggs was significantly influenced by the interactions between exposure time and the host egg:parasitoid ratio (Table 2). The linear regression indicated that the parasitism rate of T. remus on S. litura eggs decreased significantly with the increase of the host egg/parasitoid ratio for 12 and $36 \mathrm{~h}$ of exposure time. However, there was no significant linear relationship between the parasitism rate and host egg:parasitoid ratio at $24 \mathrm{~h}$ of exposure time, and the average parasitism rate ranged from $77.75 \%$ to $89.85 \%$ (Figure 4 ). 
Table 2. Results from ANOVA analysis on the effects of exposure time, host egg:parasitoid ratio, and their interactions on the biological parameters of T. remus on S. litura eggs.

\begin{tabular}{ccccc}
\hline Parameters & Source & df & F & $p$ \\
\hline Parasitism rate (\%) & ET & 2 & 41.753 & $<0.0001$ \\
& HPR & 10 & 4.422 & $<0.0001$ \\
& ET $\times$ HPR & 20 & 2.364 & 0.002 \\
Emergence rate (\%) & Error & 132 & & \\
& ET & 2 & 11.101 & $<0.0001$ \\
& HPR & 10 & 0.981 & 0.463 \\
Percentage of female progeny (\%) & ET $\times$ HPR & 20 & 2.710 & $<0.0001$ \\
& Error & 132 & & \\
& ET & 2 & 5.117 & 0.007 \\
& HPR & 10 & 63.486 & $<0.0001$ \\
& ET $\times$ HPR & 20 & 3.297 & $<0.0001$ \\
No. of emerged adults/egg & Error & 132 & & \\
& ET & 2 & 4.042 & 0.02 \\
& HPR & 10 & 4.48 & $<0.0001$ \\
& ET $\times$ HPR & 20 & 1.458 & 0.107 \\
& Error & 132 & & \\
\hline
\end{tabular}

ET = exposure time, $\mathrm{HPR}=$ host egg:parasitoid ratio.

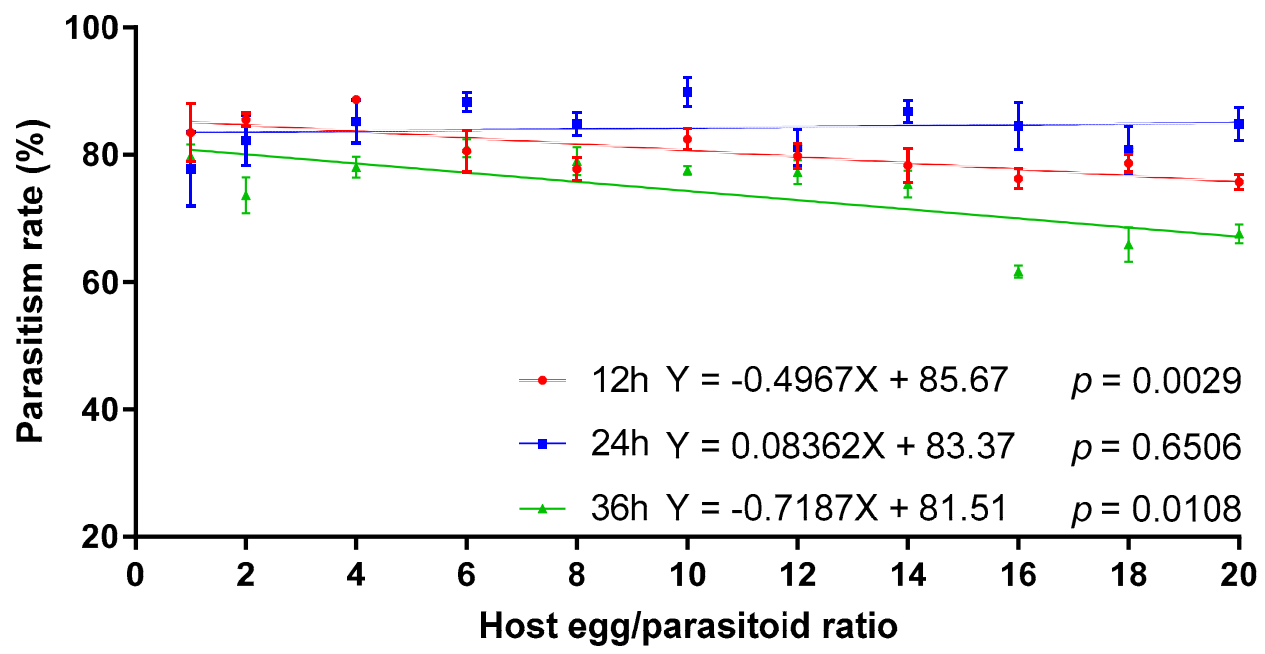

Figure 4. The effect of host egg:parasitoid ratio on parasitism rates of T. remus on S. litura eggs at different exposure times.

3.4. Offspring Fitness of T. remus under Different Combinations of Exposure Time and Host Egg:Parasitoid Ratio

No significant linear relationship was observed between the emergence rate and host egg:parasitoid ratio at any exposure time. In each treatment, the emergence rate of progeny was higher than $94.30 \%$ (Figure $5 \mathrm{~A}$ ).

The interaction between exposure time and host egg:parasitoid ratio had significant effects on the percentage of female progeny (Table 2). The percentage of female progeny significantly increased with an increased host egg:parasitoid ratio at any exposure time. The lowest percentage of female progeny was at the 1:1 host egg:parasitoid ratio, with mean percentage female for 12,24 , and $36 \mathrm{~h}$ of exposure time at $49.84 \%, 44.12 \%$, and $43.13 \%$, respectively (Figure 5B). No significant linear regression was observed between the number of emerged adults per egg and host egg:parasitoid ratio at exposure times of 12 or $24 \mathrm{~h}$. However, there was a significant negative correlation at $36 \mathrm{~h}$ of exposure time (Figure 5C). 

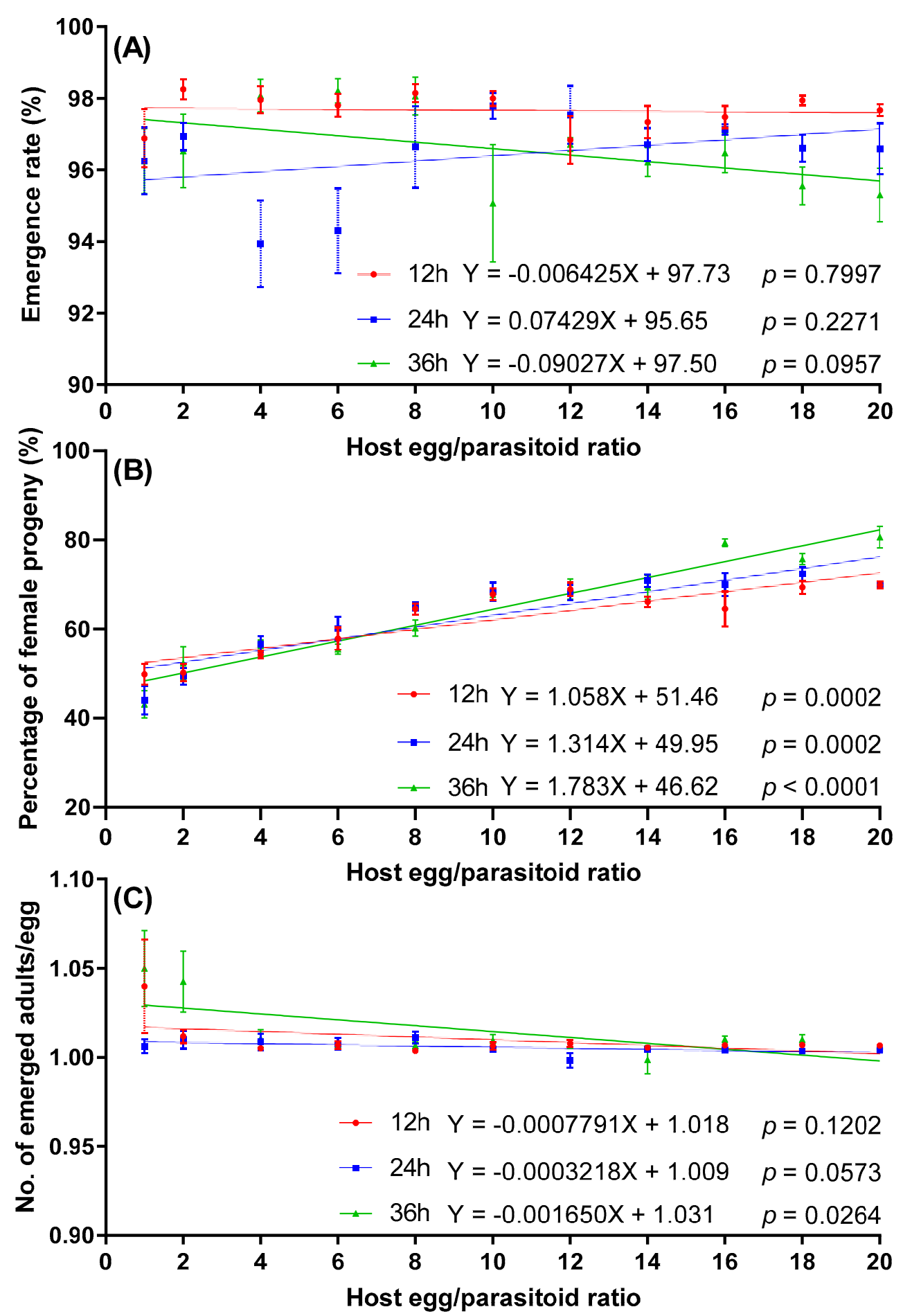

Figure 5. Effect of host egg:parasitoid ratio on emergence rate (A), percentage of female progeny (B), and number of emerged adults per egg (C) of T. remus on S. litura eggs.

\section{Discussion}

Our experiments tested the effect of photoperiod, exposure time, and host egg:parasitoid ratio on survival, offspring fitness, and reproductive potential of T. remus reared on S. litura eggs. Equally high reproductive potential was observed under the photoperiods of 12:12, 16:8, 20:4, and 24:0 L: D. The optimal host egg:parasitoid ratio was 14-20:1, and the optimal exposure time was $24 \mathrm{~h}$. These are the ideal conditions of photoperiod, exposure time, and 
host egg:parasitoid ratio for mass-rearing this strain of T. remus using S. litura eggs as the alternative host.

Despite being a promising candidate agent in the biocontrol of $S$. frugiperda, there are few studies on the physiological and reproductive performance of T. remus in China, despite this information being critical for improving mass-rearing efficiency in a laboratory. This study, to the best of our knowledge, is the first to systematically measure the effects of photoperiod on T. remus reared on S. litura eggs under controlled conditions. Our results revealed that the biological characteristics of T. remus on S. litura eggs depend closely on photoperiod: The all-dark photoperiodic condition caused the worst performance, and increasing illumination time positively affected the total number of parasitized eggs. We observed that $T$. remus frequently rested in darkness, suggesting that this species is mainly active during daytime. The increase in parasitism observed under long illumination suggests that the day-active parasitoids are time-limited rather than egg-limited [42]. Higher parasitism capacity for T. remus on S. frugiperda eggs, for T. podisi on Euschistus heros (Fabricius) eggs, and for T. pretiosum on Anagasta kuehniella (Zeller) eggs were also recorded during light compared to dark [43]. A prior study on Venturia canescens (Gravenhorst) observed that this species moved slowly, hardly tried flight, and exhibited abnormal activities under increased darkness conditions [44]. It is generally accepted that parasitoids are more active during daytime, mainly for parasitism, migration, and escaping from predators [45]. However, this positive relationship between photoperiod and parasitism cannot extend to all parasitoids: Okzan [45] found that $V$. canescens increased their egg load under continuous darkness and Mbata et al. [46] found photoperiod had no significant impact on the oviposition of Plodia interpunctella (Hübner). In addition, reports indicated that continuous daytime decreased the lifespan of $V$. canescens. This might be because the parasitoids reduced activity under darkness, which would save energy to support their survival [44]. In the present study, the shortest $T$. remus female longevity was also observed with a 24-h light photoperiod, suggesting that increased activity and parasitism during extreme illumination comes at the cost of decreased longevity. However, the effect of photoperiod on the longevity of females was not linear, with a marked decrease at $12 \mathrm{~h}$ light. The reason and mechanism for this observed sensitivity to the 12:12 L:D photoperiod need to be further explored.

In addition to photoperiod as studied in the current study, the light intensity associated with it also had a significant impact on parasitoids [47]. As reported by $\mathrm{Hu}$ et al. [47], long-day photoperiods and high light intensity produced more winged female S. pupariae progeny, and their interactions significantly impacted the developmental time and the degree of phenotypic partitioning of the progeny. Light intensity may affect flight initiation and orientation of the parasitoids, which affects their ability to find hosts $[48,49]$. Therefore, future research should pay attention to the role of light intensity in the mass-rearing and application of $T$. remus.

Understanding the relationship between photoperiod and biological characteristics of insects helps optimize insect rearing [50]. Musolin and Saulich [51] found that the growth rate of Orthoptera was retarded by short photoperiods and accelerated by long photoperiods. The current study observed a similar phenomenon, where the mean generation time was shortest under the photoperiod of 24L:0D. Exceptions exist: Hu et al. [47] found S. pupariae developed faster under prolonged darkness.

In terms of oviposition rhythm, research suggests the pre-oviposition period, namely egg retention, is prolonged with shorter photoperiods, perhaps due to reproductive diapause [52]. However, a pre-oviposition period was not observed in this study. The percentage of female progeny was highest for eggs laid on the first day of emergence regardless of photoperiod, and then gradually decreased. Diapause or dormancy for most arthropods is triggered by the interaction of colder temperatures with shorter photoperiods [53]. Malaquias et al. [54] illustrated that photoperiod is a vital ecological factor regulating oogenesis via the neuroendocrine system. In nature, the physiological and developmental preparations of organisms for seasonal reproduction, dormancy, and migration 
events generally must be done prior to that season, and day length offers a reliable reference for animals to anticipate seasonal change [55]. Therefore, photoperiodicity can serve as an anticipatory response of organisms to seasonal events and day length cues $[53,55]$. Generally, the physiology of many insects mainly focuses on reproduction when they are exposed to long-day conditions, whereas short photoperiod induces diapause as the corpora allata are deactivated, thus inhibiting the secretion of juvenile hormone [50]. In future laboratory and field studies, interactions between temperature and photoperiod should be investigated to determine whether T. remus undergoes diapause or not, and, if it does, identify the key factors inducing diapause to provide guidance for optimizing production efficiency and long-term cold storage.

The emergence rate and percentage of female progeny of T. remus were not impacted by the photoperiod. One possible explanation for these results might be the short longevity of adults, which does not provide enough time for sex determination and regulation mechanisms in response to the photoperiod experienced by the maternal generation [56]. Current study mainly evaluated the fitness of individual females under different photoperiods. However, the mass production of parasitoids usually involves a large quantity of individuals in a limited space. Under this context, local mate competition (LMC) would be triggered by the competition among males for mating access to females. To reduce or avoid this situation, mothers have fewer male offspring, resulting in a female-biased sex ratio. Although this phenomenon is beneficial to enhance their control efficiency in a natural state, we still need to pay attention to the large-scale production in the industry, and further explore the mechanisms behind this phenomenon [57].

From the perspective of reproductive potential, the net reproductive rate, intrinsic rate of increase, and finite rate of increase of T. remus under the photoperiods of more than $12 \mathrm{~h}$ light were higher than that under the illumination conditions of less than $12 \mathrm{~h}$ light. Thus, the daily illumination time for mass-rearing T. remus should be at least $12 \mathrm{~h}$.

The amount of host eggs and time available for the parasitoid to parasitize these eggs also affects mass production efficiency and the quality of the final product [58]. In this study, a relatively high host egg:parasitoid ratio (14-20:1) and exposure for a moderate time (24 h) were critical to achieve both a stable parasitism rate and a percentage of female progeny exceeding $60 \%$. When hosts are provided to a group of parasitoids, females may interfere with each other directly through displaying, fighting, and obstructing other individuals' access to the hosts; or indirectly by modifying host exploitation strategies such as sex allocation, superparasitism, and clutch size decisions $[33,59,60]$. In this study, the host egg:parasitoid ratio affected the parasitism rate differently depending on exposure time. The parasitism rate decreased with an increasing host egg:parasitoid ratio at 12 and $36 \mathrm{~h}$ of exposure time, but increased at $24 \mathrm{~h}$. Short exposure time (12 h) may not be enough for the females to parasitize oversupplied eggs, causing inefficient use of host eggs and increasing production costs [61]. Long exposure time ( $36 \mathrm{~h}$ ) may result in superparasitism due to a shortage of unparasitized hosts, decreasing the successful development and emergence rate [61]. Although previous studies demonstrated that female T. remus typically lay a single egg into each host egg, superparasitisim has been recorded in the laboratory. Parasitoid parents would lay more eggs in one host egg when host eggs are scarce or seldom encountered, rather than spending time and energy attempting to find new host eggs [22,62]. However, the limited nutrients within host eggs are usually only enough for one wasp larva to complete its development. This fierce competition for nutrients causes cannibalism and increases parasitoid larval mortality [19]. Similarly, a previous study found exposure time significantly impacted the parasitism rate of Dirhinus giffardii (Silvestri) on pupae of Zeugodacus cucurbitae (Coquillett) and Bactrocera dorsalis (Hendel), with the highest parasitism rate observed after exposure for $48 \mathrm{~h}$, followed by 72 and $24 \mathrm{~h}[63]$.

Too many male progenies during mass-rearing reduces production effectiveness [64]. In all our tests, the percentage of female progeny increased with an increasing host egg:parasitoid ratio. The lowest percentage of female progeny was observed at a 1:1 
host egg:parasitoid ratio, possibly due to superparasitism, or weak/lack of LMC. In order to maximize offspring fitness, female parasitoids determine and allocate an optimal clutch size. However, under superparasitism conditions, a larger clutch size decreases the fitness of the progeny $[62,65]$. Another possible reason is that a female parasitoid can maximize her fitness by reducing the number of sons and increasing the number of daughters under high densities of conspecifics $[66,67]$. Thus, if unable to find more eggs due to a shortage, parasitoids may unintentionally produce more males. A similar study found that, when the parasitoid host ratio was high, Tetrastichus planipennisi (Yang) not only produced more male progenies, but also had offspring of lower quality, with a smaller body size and shorter ovipositors [68]. Superparasitism was not clearly confirmed by that paper, but they found that multiple female wasps usually gathered around a single host and seemingly oviposited in the same host [68]. In our study, no significant linear regression was observed between the number of emerged adults per egg and host egg:parasitoid ratio at exposure time of 12 and $24 \mathrm{~h}$, but the significant negative correlation was recorded at $36 \mathrm{~h}$ of exposure time. Reduced offspring quantities per host when the exposure time was too long in this study suggest that host resources had been overexploited, resulting in superparasitism. Alternatively, Montoya et al. [69] suggested superparasitism might be an effective reproductive strategy for Diachasmimorpha longicaudata (Ashmead), as superparasitism ranging from moderate to high levels lead to more female progenies, ensuring the survival of at least one female larva [70]. In addition, host size and parasitoid densities also strongly affect percentage of the female progeny [69].

\section{Conclusions}

In our experiments, increased photoperiod, moderate exposure time, and host egg:parasitoid ratio improved the mass-rearing efficiency of T. remus. We advocate using more than $12 \mathrm{~h}$ of light, 24-h exposure time, and a 14-20:1 host egg:parasitoid ratio for rearing T. remus on S. litura eggs. These findings will help promote the successful, large-scale rearing of T. remus for use against $S$. frugiperda in China, though more information is needed to optimize the mass-rearing system further.

Author Contributions: Conceptualization, W.C. and L.Z.; methodology, W.C., Y.L., J.M. and L.Z.; formal analysis, W.C., Q.W., R.N., X.J. and H.Z.; writing-original draft preparation, W.C.; writingreview and editing, W.C. and L.Z.; funding acquisition, M.W. and L.Z. All authors have read and agreed to the published version of the manuscript.

Funding: This research was funded by the Major Projects of China National Tobacco Corporation (110202001032 (LS-01)), the Projects of Guizhou Tobacco Corporation (201936, 201937, and 201941), the Agricultural Science and Technology Innovation Program (CAAS-ZDRW202108), and the Science and Technology Planning Project of Inner Mongolia (2020GG0065).

Institutional Review Board Statement: Not appliable.

Data Availability Statement: Data can be provided on request from the lead author.

Acknowledgments: We thank EditSprings (https:/ / www.editsprings.com/) for providing expert linguistic services. We are very grateful to Zhenying Wang (Institute of Plant Protection, Chinese Academy of Agricultural Sciences) and Zhuhong Wang (College of Plant Protection, Fujian Agriculture and Forestry University) for their help providing experimental material.

Conflicts of Interest: The authors declare no conflict of interest.

\section{References}

1. Todd, E.L.; Poole, R.W. Keys and illustrations for the armyworm moths of the noctuid genus Spodoptera Guenee from the Western Hemisphere. Ann. Entomol. Soc. Am. 1980, 73, 722-738. [CrossRef]

2. Feldmann, F.; Rieckmann, U.; Winter, S. The spread of the fall armyworm Spodoptera frugiperda in Africa-What should be done next? J. Plant. Dis. Protect. 2019, 126, 97-101. [CrossRef]

3. CABI. Spodoptera frugiperda (Fall Armyworm). Available online: https://www.cabi.org/isc/datasheet/29810\#tonaturalEnemies (accessed on 20 September 2021). 
4. Goergen, G.; Kumar, P.L.; Sankung, S.B.; Togola, A.; Tamò, M. First report of outbreaks of the fall armyworm Spodoptera frugiperda (J E Smith) (Lepidoptera, Noctuidae), a new alien invasive pest in west and central Africa. PLoS ONE 2016, 11, e165632. [CrossRef] [PubMed]

5. China National Agro-Tech Extension and Service Center. Fall Armyworm, the Major Pest has Invaded in Yunnan, the Field Scouting and Monitoring for this Pest to Start Immediately within China. Available online: https://www.natesc.org. $\mathrm{cn} /$ news / des? id=c004cc6d-d305-40d7-a360-603f2919813d\&Category=\%E5\%85\%A8\%E6\%96\%87\%E6\%90\%9C\%E7\%B4\%A2 \&CategoryId=d6a35339-e804-4f90-bf93-927382b1fd22 (accessed on 1 September 2021).

6. China National Agro-Tech Extension and Service Center. Occurrence Trend of Spodoptera frugiperda in Autumn Maize. Available online: https: / / www.natesc.org.cn/News/des?id=b4ca3130-c5a2-4f0d-9762-f248e0b94985\&kind=HYTX\&Category= \%E6\%A4\%8D\%E6\%A3\%80\%E6\%A4\%8D\%E4\%BF\%9D\&CategoryId=07e72766-0a38-4dbd-a6a3-c823ce1172bd (accessed on 1 September 2021).

7. Wright, M.G. Biological control of invasive insect pests. In Integrated Pest Management; Abrol, D.P., Ed.; Academic Press: London, UK, 2014; pp. 267-281.

8. Henneberry, T.J. Insect pest management. In Encyclopedia of Pest Management; Pimental, D., Ed.; Taylor and Francis: Boca Raton, FL, USA, 2007; pp. 258-261.

9. Day, R.; Abrahams, P.; Bateman, M.; Beale, T.; Clottey, V.; Cock, M.; Colmenarez, Y.; Corniani, N.; Early, R.; Godwin, J.; et al. Fall armyworm: Impacts and implications for Africa. Outlooks Pest Manag. 2017, 28, 196-201. [CrossRef]

10. Wu, K.M. Management strategies of fall armyworm (Spodoptera frugiperda) in China. Plant Prot. 2020, 46, 1-5. [CrossRef]

11. Montezano, D.G.; Specht, A.; Sosa-Gómez, D.R.; Roque-Specht, V.F.; Sousa-Silva, J.C.; Paula-Moraes, S.V.; Peterson, J.A.; Hunt, T.E. Host plants of Spodoptera frugiperda (Lepidoptera: Noctuidae) in the Americas. Afr. Entomol. 2018, 26, 286-300. [CrossRef]

12. Guo, J.F.; Wu, S.Y.; Zhang, F.; Huang, C.L.; He, K.L.; Babendreier, D.; Wang, Z.Y. Prospects for microbial control of the fall armyworm Spodoptera frugiperda: A review. BioControl 2020, 65, 647-662. [CrossRef]

13. Bhusal, S.; Chapagain, E. Threats of fall armyworm (Spodoptera frugiperda) incidence in Nepal and it's integrated management-A review. J. Agr. Nat. Resour. 2020, 3, 345-359. [CrossRef]

14. Tambo, J.A.; Day, R.K.; Lamontagne-Godwin, J.; Silvestri, S.; Beseh, P.K.; Oppong-Mensah, B.; Phir, N.A.; Matimelo, M. Tackling fall armyworm (Spodoptera frugiperda) outbreak in Africa: An analysis of farmers' control actions. Int. J. Pest Manag. 2020, 66, 298-310. [CrossRef]

15. Wang, Z.Z.; Liu, Y.Q.; Shi, M.; Huang, J.H.; Chen, X.X. Parasitoid wasps as effective biological control agents. J. Integr. Agr. 2019, 18, 705-715. [CrossRef]

16. Okuma, D.M.; Bernardi, D.; Horikoshi, R.J.; Bernardi, O.; Silva, A.P.; Omoto, C. Inheritance and fitness costs of Spodoptera frugiperda (Lepidoptera: Noctuidae) resistance to spinosad in Brazil. Pest Manag. Sci. 2017, 78, 1441-1448. [CrossRef] [PubMed]

17. Masry, S.H.D.; El-Wakeil, N. Egg parasitoid production and their role in controlling insect pests. In Cottage Industry of Biocontrol Agents and Their Applications; El-Wakeil, N., Saleh, M., Abu-hashim, M., Eds.; Springer: Cham, Switzerland, 2019 ; pp. 3-47.

18. Salazar-Mendoza, P.; Rodriguez-Saona, C.; Fernandes, O.A. Release density, dispersal capacity, and optimal rearing conditions for Telenomus remus, an egg parasitoid of Spodoptera frugiperda, in maize. Biocontrol Sci. Technol. 2020, 30, 1040-1059. [CrossRef]

19. Cave, R.D. Biology, ecology and use in pest management of Telenomus remus. Biocontrol News Inf. 2000, 21, 21-26.

20. Waddill, H.; Whitcomb, W.H. Release of Telenomus remus (Hym. Scelionidae) against Spodoptera frugiperda (Lep.: Noctuidae) in Florida, U.S.A. Entomophaga 1982, 27, 159-162. [CrossRef]

21. Pomari, A.F.; Bueno, A.F.; Bueno, R.C.O.F.; Junior, M.; de Oliceriras, A.; Fonseca, A.C.P.F. Releasing number of Telenomus remus (Nixon) (Hymenoptera: Platygastridae) against Spodoptera frugiperda Smith (Lepidoptera: Noctuidae) in corn, cotton and soybean. Cienc. Rural 2013, 43, 377-382. [CrossRef]

22. Dong, H.; Zhu, K.H.; Zhao, Q.; Bai, X.P.; Zhou, J.C.; Zhang, L.S. Morphological defense of the egg mass of Spodoptera frugiperda (Lepidoptera: Noctuidae) affects parasitic capacity and alters behaviors of egg parasitoid wasps. J. Asia-Pac. Entomol. 2021, 24, 671-678. [CrossRef]

23. Finney, G.L.; Fisher, T.W. Culture of entomophagous insects and their host. In Biological Control of Insect Pests and Weeds; De Bach, P., Sclinger, E.I., Eds.; Chapman \& Hall Ltd.: London, UK, 1964; pp. 328-355.

24. Parra, J.R.P. Mass rearing of egg parasitoids for biological control programs. In Egg Parasitoids in Agroecosystems with Emphasis on Trichogramma; Consoli, F.L., Parra, J.R.P., Zucchi, R.A., Eds.; Springer: Dordrecht, The Netherlands, 2010; pp. $267-292$.

25. Pomari-Fernandes, A.; Bueno, A.F.; de Bortoli, S.A.; Favetti, B.M. Dispersal capacity of the egg parasitoid Telenomus remus Nixon (Hymenoptera: Platygastridae) in maize and soybean crops. Biol. Control 2018, 126, 158-168. [CrossRef]

26. Queiroz, A.P.; Bueno, A.F.; Pomari-Fernandes, A.; Grande, M.L.M.; Bortolotto, O.C.; Silva, D.M. Quality control of Telenomus remus (Hymenoptera: Platygastridae) reared on the factitious host Corcyra cephalonica (Lepidoptera: Pyralidae) for successive generations. Bull. Entomol. Res. 2017, 107, 791-798. [CrossRef] [PubMed]

27. Queiroz, A.P.; Bueno, A.F.; Pomari-Fernandes, A.; Grande, M.L.M.; Bortolotto, O.C.; Silva, D.M. Low temperature storage of Telenomus remus (Nixon) (Hymenoptera: Platygastridae) and its factitious host Corcyra cephalonica (Stainton) (Lepidoptera: Pyralidae). Neotrop. Entomol. 2017, 46, 182-192. [CrossRef] [PubMed]

28. Pomari-Fernandes, A.; Queiroz, A.P.; Bueno, A.F.; Sanzovo, A.W.; De Bortoli, S.A. The importance of relative humidity for Telenomus remus (Hymenoptera: Platygastridae) parasitism and development on Corcyra cephalonica (Lepidoptera: Pyralidae) and Spodoptera frugiperda (Lepidoptera: Noctuidae) eggs. Ann. Entomol. Soc. Am. 2015, 108, 11-17. [CrossRef] 
29. Dai, P.; Sun, J.W.; Chen, Y.M.; Bao, H.P.; Zhang, L.S.; Nkunika, P.O.Y.; Zang, L.S. Discovery of three egg parasitoid species for the control of Spodoptera frugiperda (Smith). J. Jilin. Agric. Univ. 2019, 41, 505-509. [CrossRef]

30. Huo, L.X.; Zhou, J.C.; Ning, S.F.; Zhao, Q.; Zhang, L.X.; Zhang, Z.T.; Zhang, L.S.; Dong, H. Biological characteristics of Telenomus remus against Spodoptera frugiperda and Spodoptera litura eggs. Plant Prot. 2019, 45, 60-64. [CrossRef]

31. Chen, W.B.; Li, Y.Y.; Wang, M.Q.; Mao, J.J.; Zhang, L.S. Evaluating the potential of using Spodoptera litura eggs for mass-rearing Telenomus remus, a promising egg parasitoid of Spodoptera frugiperda. Insects 2021, 12, 384. [CrossRef] [PubMed]

32. Van Nieuwenhove, G.A.; Bezdjian, L.P.; Ovruski, S.M. Effect of exposure time and ratio of hosts to female parasitoids on offspring production of Diachasmimorpha longicaudata (Hymneoptera: Braconidae) reared on Anastrepha fraterculus (Diptera: Tephritidae) larvae. Fla. Entomol. 2012, 95, 99-104. [CrossRef]

33. Wang, X.G.; Aparicio, E.M.; Duan, J.J.; Gould, J.; Hoelmer, K.A. Optimizing parasitoid and host densities for efficient rearing of Ontsira mellipes (Hymenoptera: Braconidae) on Asian Longhorned Beetle (Coleoptera: Cerambycidae). Environ. Entomol. 2020, 49, 1041-1048. [CrossRef]

34. Wei, K.; Gao, S.K.; Tang, Y.L.; Wang, X.Y.; Yang, Z.Q. Determination of the optimal parasitoid-to-host ratio for efficient mass-rearing of the parasitoid, Sclerodermus pupariae (Hymenoptera: Bethylidae). J. Appl. Entomol. 2017, 141, 181-188. [CrossRef]

35. Wang, Z.Y.; He, K.L.; Zhang, F.; Lu, X.; Babendreier, D. Mass rearing and release of Trichogramma for biological control of insect pests of corn in China. Biol. Control 2014, 68, 136-144. [CrossRef]

36. Zilch, K.C.F.; Jahnke, S.M.; Köhler, A.; Bender, E. Effect of diet, photoperiod and host density on parasitism of Anisopteromalus calandrae on the tobacco beetle and biological parameters of the parasitoid. Am. J. Plant. Sci. 2017, 8, 3218-3232. [CrossRef]

37. Pomari, A.F.; Bueno, A.F.; Bueno, R.C.O.F.; Menezes, A.O. Telenomus remus Nixon egg parasitization of three species of Spodoptera under different temperatures. Neotrop. Entomol. 2013, 42, 399-406. [CrossRef]

38. Gautam, R.D. Effect of different temperatures and relative humidities on the efficiency of parasitoid, Telenomus remus Nixon (Scelionidae: Hymenoptera) in the laboratory. J. Entomol. Res. 1986, 10, 34-39.

39. Greene, G.L.; Leppla, N.C.; Dickerson, W.A. Velvetbean caterpillar: A rearing procedure and artificial medium. J. Econ. Entomol. 1976, 69, 487-488. [CrossRef]

40. Chen, Q.J.; Li, G.H.; Pang, Y. A simple artificial diet for mass rearing of some noctuid species. Entomol. Knowl. 2000, 37, 325-327.

41. Huang, S.S.; Dai, Z.Y.; Wu, D.Z. Compilation and application of life table of Trichogramma population. Acta. Phytoph. Sin. 1996, 23, 209-212.

42. Kehoe, R.; Sanders, D.; Cruse, D.; Silk, M.; Gaston, K.J.; Bridle, J.R.; van Veen, F. Longer photoperiods through range shifts and artificial light lead to a destabilizing increase in host-parasitoid interaction strength. J. Anim. Ecol. 2020, 89, 2508-2516. [CrossRef]

43. Grande, M.L.M.; Queiroz, A.P.; Gonçalves, J.; Hayashida, R.; Ventura, M.U.; Bueno, A.F. Impact of environmental variables on parasitism and emergence of Trichogramma pretiosum, Telenomus remus and Telenomus podisi. Neotrop. Entomol. 2021, 50, 605-614. [CrossRef] [PubMed]

44. Scott, S.M.; Barlow, C.A. Effect of prey availability during development on the reproductive output of Metasyrphus corollae (Diptera: Syrphidae). Environ. Entomol. 1984, 13, 669-674. [CrossRef]

45. Ozkan, C. Effect of food, light and host instar on the egg load of the synovigenic endoparasitoid Venturia canescens (Hymenoptera: Ichneumonidae). J. Pest Sci. 2007, 80, 79-83. [CrossRef]

46. Mbata, G.N.; Warsi, S.; Payton, M.E. Influence of temperature and photoperiod on the fecundity of Habrobracon hebetor Say (Hymenoptera: Braconidae) and on the paralysis of host larvae, Plodia interpunctella (Hübner) (Lepidoptera: Pyralidae). Insects 2021, 12, 753. [CrossRef]

47. Hu, S.; Wang, X.Y.; Yang, Z.Q.; Duan, J.J. Effects of photoperiod and light intensity on wing dimorphism and development in the parasitoid Sclerodermus pupariae (Hymenoptera: Bethylidae). Biol. Control 2019, 133, 117-122. [CrossRef]

48. Gu, H.; Dorn, S. How do wind velocity and light intensity influence host-location success in Cotesia glomerata (Hym., Braconidae)? J. Appl. Entomol. 2001, 125, 115-120. [CrossRef]

49. Zilahi-balogh, G.M.G.; Shipp, J.L.; Cloutier, C.; Brodeur, J. Influence of light intensity, photoperiod, and temperature on the efficacy of two aphelinid parasitoids of the greenhouse whitefly. Environ. Entomol. 2006, 35, 581-589. [CrossRef]

50. Mousumi, D.; Ganguly, A.; Haldar, P. Determination of optimum temperature and photoperiod for mass production of Oxya hyla hyla (Serville). Turk. J. Zool. 2012, 36, 329-339. [CrossRef]

51. Musolin, D.L.; Saulich, A.K. Photoperiodic control of nymphal growth in true bugs (Heteroptera). Entomol. Rev. 1997, 77, 768-780.

52. Reznik, S.Y.; Vaghina, N.P. Effect of photoperiod on parasitization by Trichogramma principium (Hymenoptera: Trichogrammatidae). Eur. J. Entomol. 2007, 104, 705-713. [CrossRef]

53. Wang, S.; Tan, X.L.; Guo, X.J.; Zhang, F. Effect of temperature and photoperiod on the development, reproduction, and predation of the predatory ladybird Cheilomenes sexmaculata (Coleoptera: Coccinellidae). J. Econ. Entomol. 2013, 106, 2621-2629. [CrossRef]

54. Malaquias, J.B.; Ramalho, F.S.; Fernandes, F.S.; Souza, J.V.S.; Azeredo, T.L. Effects of photoperiod on the development and growth of Podisus nigrispinus, a predator of cotton leafworm. Phytoparasitica 2009, 37, 241-248. [CrossRef]

55. Bradshaw, W.E.; Holzapfel, C.M. Evolution of animal photoperiodism. Annu. Rev. Ecol. Evol. Syst. 2007, 38, 1-25. [CrossRef]

56. Qian, H.T.; Cong, B.; Zhang, Z.L.; Dai, Q.H. Effect of some environmental and biological factors on reproductive characters of Trichogramma spp. Afr. J. Agric. Res. 2013, 8, 2195-2203. [CrossRef]

57. Somjee, U.; Ablard, K.; Crespi, B.; Schaefer, P.W.; Gries, G. Local mate competition in the solitary parasitoid wasp Ooencyrtus kuvanae. Behav. Ecol. Sociobiol. 2011, 65, 1071-1077. [CrossRef] 
58. Chambers, D.L. Quality control in mass rearing. Annu. Rev. Entomol. 1977, 22, 289-308. [CrossRef]

59. Yazdani, M.; Keller, M. Mutual interference in Dolichogenidea tasmanica (Cameron) (Hymenoptera: Braconidae) when foraging for patchily-distributed light brown apple moth. Biol. Control 2015, 86, 1-6. [CrossRef]

60. Gobault, M.; Mack, A.F.S.; Hardy, C.W. Encountering competitors reduces clutch size and increases offspring size in a parasitoid with female-female fighting. Proc. R. Soc. B 2007, 274, 2571-2577. [CrossRef]

61. Smith, S.M. Biological control with Trichogramma: Advances, successes, and potential of their use. Annu. Rev. Entomol. 1996, 41, 375-406. [CrossRef]

62. Godfray, H.C.J. Parasitoids: Behavioral and Evolutionary Ecology; Princeton University Press: Princeton, NJ, USA, 1994.

63. Ullah, F.; Farooq, M.; Honey, S.F.; Zada, N. Parasitism potential of Dirhinus giffardii (Silvestri) (Hymenoptera: Chalcididae) on pupae of the fruit fly species, Zeugodacus cucurbitae (Coquillett) and Bactrocera dorsalis (Hendel) (Diptera: Tephritidae), during variable exposure durations. Egypt. J. Biol. Pest Control 2021, 31, 9. [CrossRef]

64. Li, L.; Wei, L.; Liu, Z.D.; Sun, J.H. Host adaptation of a gregarious parasitoid Sclerodermus harmandi in artificial rearing. BioControl 2010, 55, 465-472. [CrossRef]

65. Zhou, J.C.; Liu, Q.Q.; Wang, Q.R.; Ning, S.F.; Che, W.N.; Dong, H. Optimal clutch size for quality control of bisexual and Wolbachia-infected thelytokous lines of Trichogramma dendrolimi Matsumura (Hymenoptera: Trichogrammatidae) mass reared on eggs of a substitutive host, Antheraea pernyi Guérin-Méneville (Lepidoptera: Saturniidae). Pest Manag. Sci. 2020, 76, 2635-2644. [CrossRef]

66. Chen, W.B.; He, K.L.; Wang, Q.Y.; Wang, Z.Y. Effects of yellow peach moth Conogethes punctiferalis egg age on parasitism and oviposition behaviour of four indigenous Trichogramma strains in China. Biocontrol Sci. Technol. 2021, 31, 739-753. [CrossRef]

67. Godin, C.; Boivin, G. Effects of host age on parasitism and progeny allocation in Trichogrammatidae. Entomol. Exp. Appl. 2000, 97, 149-160. [CrossRef]

68. Duan, J.J.; Oppel, C. Critical rearing parameters of Tetrastichus planipennisi (Hymenoptera: Eulophidae) as affected by host plant substrate and host-parasitoid group structure. J. Econ. Entomol. 2012, 105, 792-801. [CrossRef]

69. Montoya, P.; Cancino, J.; Pérez-Lachaud, G.; Liedo, P. Host size, superparasitism and sex ratio in mass-reared Diachasmimorpha longicaudata, a fruit fly parasitoid. BioControl 2011, 56, 11-17. [CrossRef]

70. González, P.I.; Montoya, P.; Perez-Lachaud, G.; Cancino, J.; Liedo, P. Superparasitism in mass reared Diachasmimorpha longicaudata (Ashmead) (Hymenoptera: Braconidae), a parasitoid of fruit flies (Diptera: Tephritidae). Biol. Control 2007, 40, 320-326. [CrossRef] 